\title{
Analogue and digital
}

\section{Sean Cubitt}

\section{KEYWORDS: aesthetics - analogue - digital}

In the brief fifty years of its history, computer arts have given rise to a number of schools. Early practitioners like Jordan Belson were interested in machinic contributions to the spiritual aspects of abstraction noted in the early 20th century by Malevich, Kandinsky and Mondrian. Certain artists insist that only engineering in software and hardware constitutes digital art, while the use of existing programmes and machines is dilettantism. Other schools have focused on interactivity, immersion or networking as constitutive factors of a distinctively digital art. And some artists (Young Hae Cheung, Vuk Cosic) renounce all high-level programming and interaction. While some commentators, especially in the 1990s, sought to distinguish the digital aesthetic from all previous aesthetic modes, increasingly scholars and critics have come round to a disputed and various but common belief in continuities between digital and previous arts.

The distinction when stated technically is minor. Analogue media like photography create an analogy with the world observed by establishing a one-to-one correspondence between, in this example, light falling on a surface, and the lightresponsive chemicals applied to it. Such correspondences underpinned late 19th and early 20th century theories of realism and technologies of fidelity in fields like recorded music and cinematography. Digital media use a different system. Instead of tracking the real in the manner of a phonograph needle agitated by the vibrations of the air, digital devices sample ambient sound in discrete packages. Though the sampling rate is extremely fast, and gives therefore a more accurate 
rendering of the realia recorded, there is inevitably a minute gap between samples which the digital recording can never fill, unlike analog, whose relatively sluggish response is nonetheless continuous rather than sampled.

The apparent simplicity of the distinction masks a more significant property of digital storage. Data held in a computer is stored as an array of digits encoded as electrical impulses, magnetic orientation or optical arrays. From the standpoint of the computer, any input will always appear as mathematical, and any data can be output in any format. Effectively, an audio input can be output as a video image, as text, as a 3D model, as an instruction set for a manufacturing process, or any other digital format that can be attached to the computer. The manipulability of the data once stored, though not unprecedented, is easily accessible to ordinary computer users, and proliferates in montage and in the alteration of photographs, texts and digital recordings. Several authors have attempted to use such effects as distinguishing factors in describing a single, universal digital aesthetic. However, in the early years of the 21st century, it became apparent not only that older aesthetic principles still hold good in such areas as digitally animated films and digitally generated dance music, but that many modes of software have evolved their own specific aesthetic properties and practices. In visual media, the distinction between bitmap ('raster') graphics, based on a grid, and vector graphics based on algorithms, has become the basis of discrete analyses of the aesthetics of specific programmes and software interfaces (for example Munster 2003), while computer games (Aarseth 1997), 'post-cinema' (Shaw and Weibel 2003) and various modes of digital music (Miller 2004) have increasingly been distinguished from any unitary aesthetic. The proliferation of digital media across professional disciplines, and the increasing embedding of digital media invisibly within architecture, artefacts, and human beings indicates both that the unification of digital aesthetics around any core group of properties is decreasingly likely, and that the specificity of the digital may decline as digital media are more and more embedded in the landscapes of everyday work, transport, housework and education. Alternatively, this embedding process may herald the end of aesthetics as a preserve of leisure ('disinterested') activities. 
WORKS CITED

Aarseth, Espen (1997), Cybertext: Perspectives on Ergodic Literature. Baltimore: Johns Hopkins University Press.

Miller, Paul D aka DJ Spooky That Subliminal Kid (2004), Rhythm Science. Cambridge MA.: Mediawork/MIT Press.

Munster, Anna (2003), 'Compression and the Intensification of Visual Information in Flash Aesthetics' in Adrian Miles (ed), MelbourneDAC 2003 streamingworlds, long paper proceedings of the 5th International Digital Arts and Culture Conference Melbourne DAC May 2003. Melbourne: RMIT University School of Applied Communication, 150-9.

Shaw, Jeffrey and Peter Weibel (eds) 2003), Future Cinema: The Cinematic Imaginary After Film. Karlsruhe: ZKM and Cambridge MA.: MIT Press. 


\section{University Library}

- MINERVA A gateway to Melbourne's research publications

Minerva Access is the Institutional Repository of The University of Melbourne

Author/s:

CUBITT, SEAN

Title:

Analogue and digital

Date:

2006

Citation:

Cubitt, Professor Sean (2006) Analogue and digital, in Theory, Culture and Society, 23(2/3), 250-251.

Publication Status:

Published

Persistent Link:

http://hdl.handle.net/11343/34858

File Description:

Analogue and digital 


\section{University Library}

\section{- M M I E E R VA A gateway to Melbourne's research publications}

Minerva Access is the Institutional Repository of The University of Melbourne

Author/s:

CUBITT, S

Title:

Analogue and Digital

Date:

2006

Citation:

CUBITT, S. (2006). Analogue and Digital. Theory, Culture \& Society, 23 (2/3), pp.250-251. https://doi.org/10.1177/0263276406023002151.

Persistent Link:

http://hdl.handle.net/11343/28168 